J. Ris. \& Ap. Mat. Vol. 04 No. 02 (2020) pp. 74-81

Jurnal Riset dan Aplikasi Matematika

e-ISSN: 2581-0154

URL: journal.unesa.ac.id/index.php/jram

\title{
PENENTUAN HARGA CALL OPSI EROPA MENGGUNAKAN MODEL BLACK-SCHOLES, ANTITHETIC VARIATE DAN BINOMIAL
}

\author{
FAHreZAl Zubedi $^{1 *}$, Franky Alfrits OrOH $^{2}$, Muftih Alwi Aliu ${ }^{3}$ \\ 1,2,3 Jurusan Matematika, FMIPA Universitas Negeri Gorontalo \\ *fahrezal@ung.ac.id
}

\begin{abstract}
ABSTRAK
Ada beberapa cara dalam menentukan harga call opsi Eropa di antaranya Model Black-Scholes, Monte Carlo dengan teknik Antithetic Variate dan Binomial. Penelitian ini bertujuan untuk menentukan harga call opsi Eropa dengan menggunakan model Black-Scholes, Antithetic Variate dan Binomial serta menganalisis harga call opsi Eropa yang dihitung menggunakan Antithetic Variate dan model Binomial berdasarkan harga call opsi Eropa yang dihitung menggunakan model Black-Scholes sebagai solusi analitik. Pengaplikasian model-model dalam penelitian ini menggunakan data harga penutupan saham harian dari PT Agro Lestari Tbk pada tanggal 1 Mei 2019 sampai dengan 30 April 2020 sehingga diperoleh harga saham awal $\left(S_{0}\right)=$ Rp. 10.875, tingkat suku bunga sebesar 4,5\%, volatilitas sebesar $50,88 \%$ per hari dan harga pelaksanaan $(K)=$ Rp. 12.000. Harga call opsi Eropa menggunakan Model Black-Scholes sebesar Rp. 1195,93. Pada Simulasi Monte Carlo dengan teknik Antithetic Variate ke10.000.000 menghasilkan harga call opsi Eropa Rp. 1219,312 dengan standar error 0,5751809, sedangkan model Binomial menghasilkan harga call opsi Eropa sebesar Rp. 1235,216. Hasil penelitian ini menunjukkan bahwa semakin banyak simulasi pada teknik Antithetic Variate dan semakin banyak langkah pada model Binomial menghasilkan harga call opsi Eropa yang konvergen ke harga call opsi Eropa model Black-Scholes.
\end{abstract}

Kata Kunci: Antithetic Variate, Binomial, Black-Scholes, Opsi Call Eropa.

\begin{abstract}
There are several ways to determine the price of European call option including the Black-Scholes Models, Monte Carlo with the Antithetic Variate technique and Binomial. This research aims to determine the price of European call option using the Black-Scholes, Antithetic Variate and Binomial and to analyze the results of European call option prices obtained by the Antithetic Variate and Binomial models based on European call option prices calculated using the Black-Scholes model as an analytical solution. Moreover, application models in this study uses data from the closing price of the daily stock of PT.Agro Lestari.Tbk on May 1, 2019 to April 30, 2020 so that the obtained stock price $\left(S_{0}\right)=$ Rp.10.875 an interest rate of $4.5 \%$, volatility of $50.88 \%$ and the strike price $(K)=$ Rp. 12,000 . European call option prices use the black-scholes model of Rp.1195,93. Furthermore, in Monte Carlo simulation with the $10.000 .000^{\text {th }}$ Antithetic Variate technique produces an European call option price of Rp.1219.312 with an error standard of 0,5751809, while the Binomial model produces a price of an European call option amounting to Rp.1235,216. The results of this study indicate that the more Monte Carlo simulations with the Antithetic Variate technique and the greater the partition Binomial model produces the price of a European call option converging to the European call option price of a BlackScholes model.
\end{abstract}

Keywords: Antithetic Variate, Binomial, Black-Scholes, European Call Option 


\section{Pendahuluan}

Investasi adalah memanfaatkan aset yang dimiliki seseorang untuk hal yang lebih bernilai dengan tujuan untuk memperoleh keuntungan yang lebih dengan biaya minimum. Seorang investor harus bersedia menanggung risiko tinggi apabila melakukan suatu investasi. Opsi merupakan suatu solusi untuk meminimalisasi risiko tersebut. Opsi adalah hak, bukan kewajiban, dari pemegang saham untuk menjual atau membeli suatu aset pada waktu dan harga tertentu. Biasanya aset yang menjadi dasar adalah saham. Opsi dapat dikelompokkan menjadi dua kategori utama yaitu opsi call dan opsi put. Opsi call merupakan hak kepada holder untuk membeli aset dari writer pada harga yang sudah disepakati dan waktu yang telah ditentukan. Berdasarkan waktu jatuh tempo, opsi terbagi atas dua jenis yaitu opsi Eropa dan opsi Amerika, Opsi Eropa merupakan opsi yang hanya dapat dieksekusi pada saat jatuh tempo [1]. Jadi, Opsi call Eropa memberikan hak kepada holder untuk membeli aset pada saat jatuh tempo.

Ada beberapa cara yang digunakan dalam perhitungan harga call opsi Eropa, di antaranya adalah model Black-Scholes, Binomial dan Simulasi Monte Carlo. Kebanyakan penelitian tentang perhitungan harga call opsi Eropa hanya menunjukkan harga call opsi Eropa menggunakan model-model yang digunakan dan membandingkan model yang memberikan solusi analitik dengan model yang memberikan solusi numerik. Pada Simulasi Monte Carlo terdapat teknik reduksi variansi yaitu Antithetic variate. Antithetic variate merupakan suatu teknik pengurangan varians dengan mengganti peubah acak dengan peubah acak lainnya yang berkorelasi negative tanpa meningkatkan ukuran sampel dalam mensimulasi harga opsi dan lebih cepat konvergensinya [2]. Pada tahun 2018 Putri, Dharmawan dan Sumarjaya [3] telah melakukan penelitian tentang penentuan harga put Opsi Barrier Eropa dengan menggunakan Antithetic Variate. Pada penelitian tersebut menghasilkan harga opsi put dengan standar error yang lebih kecil daripada Simulasi Monte Carlo Standar.

Model Binomial dapat digunakan dengan asumsi bahwa pergerakan harga aset hanya memiliki dua kemungkinan kejadian, yaitu harga aset naik atau harga aset turun [4]. Model Black-Scholes merupakan model yang digunakan untuk menentukan harga opsi yang telah diterima oleh industri keuangan. Model ini dikembangkan oleh Fisher Black dan Myron Scholes. Pada tahun 2017 Mooy, Rusgiyono dan Rahmawati [5] telah melakukan penelitian tentang Penentuan harga opsi put dan call tipe Eropa terhadap Saham menggunakan Model BlackScholes. Pada penelitian tersebut menyatakan bahwa kontrak opsi call merupakan opsi yang direkomendasikan untuk dibeli oleh investor karena memiliki harga opsi yang lebih kecil daripada harga teoritisnya. Oleh karena itu, penelitian ini bertujuan untuk menentukan harga call opsi Eropa dengan menggunakan model Black-Scholes, Binomial dan Antithetic Variate. Selain itu, penelitian ini bertujuan untuk menganalisis harga call opsi Eropa yang dihitung menggunakan Antithetic Variate dan model Binomial berdasarkan harga call opsi Eropa yang dihitung menggunakan model Black-Scholes sebagai solusi analitik.

\section{Tinjauan Pustaka}

\subsection{Return dan Volatilitas}

Return merupakan hasil atau tingkat pengembalian yang diperoleh setelah melakukan investasi. Nilai return saham pada umumnya berdistribusi normal. Ada beberapa cara untuk menentukan return saham yaitu dengan menggunakan Gross Return, Net Return dan Log Return. Pada penelitian ini menggunakan Log Return untuk menentukan return saham. Log Return atau disebut juga continuously compounded return dinotasikan dengan dan didefinisikan sebagai berikut:

$$
R_{t}=\ln \left(1+R_{t}\right) \approx \ln \frac{S_{t}}{S_{t-1}}
$$


dengan $S_{t}$ merupakan data harga penutupan saham harian pada waktu $t$ [6]. Volatilitas adalah besarnya fluktuasi (perubahan harga) dari sebuah saham. Semakin besar volatilitas saham, maka semakin besar kemungkinan mengalami keuntungan atau kerugian. Rumus dari Volatilitas adalah sebagai berikut:

$$
\sigma=\sqrt{\frac{\sum_{t=1}^{n}\left(R_{t}-\bar{R}_{t}\right)}{n-1} * n}
$$

dimana $\sigma$ merupakan volatilitas, $n$ merupakan banyaknya hari perdagangan dalam satu tahun, $R_{t}$ merupakan return harian dan $\bar{R}_{t}$ merupakan estimasi rataan dari return harian dengan menggunakan rumus sebagai berikut [5]:

\subsection{Model Black-Scholes}

$$
\bar{R}_{t}=\frac{\sum_{t=1}^{n} R_{t}}{n}
$$

Persamaan Black-Scholes untuk menghitung harga call opsi Eropa sebagai berikut:

$$
C=S_{0} N\left(d_{1}\right)-K e^{-r t} N\left(d_{2}\right)
$$

dengan nilai $N\left(d_{1}\right)$ dan $N\left(d_{2}\right)$ merupakan fungsi distribusi normal kumulatif untuk $d_{1}$ dan $d_{2}$. Perhitungan $d_{1}$ dan $d_{2}$ dapat dihitung sebagai berikut [1]:

$$
\begin{aligned}
& d_{1}=\frac{\ln \left(\frac{S_{0}}{K}\right)+\left(r+\frac{1}{2} \sigma^{2}\right) T}{\sigma \sqrt{T}} \\
& d_{2}=d_{1}-\sigma \sqrt{T}
\end{aligned}
$$

\subsection{Monte Carlo-Antithetic Variate}

Monte-Carlo merupakan simulasi metode numerik dengan ketidakpastian tinggi. Metode Monte-Carlo mengandung langkah pengambilan bilangan acak dengan asumsi mengikuti distribusi tertentu dan digunakan untuk menghitung harga opsi [1].

Simulasi monte carlo adalah sebuah pengujian bilangan acak yang menggunakan pesamaan matematik. Prediksi menggunakan Monte Carlo mewajibkan pengujian data yang sama dilakukan berulang-ulang dengan menggunakan bilangan acak yang berlainan tapi memiliki keseragaman sehingga informasi dapat dihasilkan lebih efisien [7].

Perhitungan harga opsi menggunakan metode antithetic variate mengikuti gerak Brown geometric dengan cara membangkitkan dua bilangan acak yang berdistribusi normal standar dan dilanjutkan dengan menentukan nilai duga [8].

$$
S^{+}=S_{t_{0}} e^{\left(r-\frac{\sigma^{2}}{2}\right) \Delta t+\sigma Z \sqrt{\Delta t}}
$$

dan nilai dugaan untuk rumus antithetic adalah:

$$
S^{-}=S_{t_{0}} e^{\left(r-\frac{\sigma^{2}}{2}\right) \Delta t-\sigma Z \sqrt{\Delta t}}
$$

Nilai penduga akhirnya diketahui dengan menggabungkan kedua penduga yaitu: 


$$
S_{\text {gabungan }}=\frac{S^{+}+S^{-}}{2}
$$

Pembentukan penduga antithetic bertujuan untuk membentuk penduga baru dengan varians lebih kecil. Diberikan varians dari $S_{\text {gabungan }}$ yaitu:

$$
\begin{aligned}
\operatorname{Var} S_{\text {gabungan }} & =\operatorname{Var}\left(\frac{S^{+}+S^{-}}{2}\right) \\
& =\frac{\operatorname{Var}\left(S^{+}\right)+\operatorname{Var}\left(S^{-}\right)+2 \operatorname{Cov}\left(S^{+}, S^{-}\right)}{2}
\end{aligned}
$$

Untuk menghitung standar error dari Monte Carlo-Antithetic Variate sebagai berikut:

$$
S E=\frac{\sqrt{\text { Var } S_{\text {gabungan }}}}{\sqrt{M}}
$$

dimana $\sqrt{\text { Var } S_{\text {gabungan }}}$ merupakan standar deviasi dari $S_{\text {gabungan }}$, dan $M$ adalah banyaknya simulasi. Payoff dari harga call opsi Eropa sebagai berikut:

$$
\begin{aligned}
& \max \left(S^{+}-K, 0\right) \\
& \max \left(S^{-}-K, 0\right)
\end{aligned}
$$

Harga perkiraan opsi call tipe Eropa sebagai berikut:

$$
\begin{aligned}
& C_{1}=\frac{1}{M} \sum_{i=1}^{M} e^{-r T} \max \left(S_{i}^{+}-K, 0\right) \\
& C_{2}=\frac{1}{M} \sum_{i=1}^{M} e^{-r T} \max \left(S_{i}^{-}-K, 0\right)
\end{aligned}
$$

Sehingga harga call opsi Eropa sebagai berikut:

$$
\bar{C}=\frac{C_{1}+C_{2}}{2}
$$

\subsection{Model Binomial}

Selang waktu $[0, T]$ dibagi menjadi $n$ selang bagian sama panjang dengan titik bagi $0=$ $t_{0}<t_{1}<\cdots<t_{n}=T$, dengan $t_{i}=i \Delta t(i=0,1, \ldots, n), \Delta t=\frac{T}{n}$ dan $S_{\mathrm{i}}=S\left(t_{i}\right)$ harga saham pada saat $t_{i}$. Asumsi sebagai berikut [1]:

1. Dalam selang waktu harga saham dapat naik atau turun menjadi $S \rightarrow S u$ dan $S \rightarrow S d$ dengan $0<d<1<u$.

2. Peluang harga saham naik $\mathrm{P}($ naik $)=p$

3. Ekspektasi return dengan harga saham besarnya sama dengan risk-free interest rate $r$. sehingga untuk harga saham $S$ yang bergerak secara acak dari $S$ yang bergerak secara acak dari $S_{i}$ pada saat $t_{i+1}$ ini berarti $E\left(S_{i+1}\right)=S_{i} e^{r \Delta t}$ (Ekspektasi model kontinu).

Persamaan model $n$ langkah untuk opsi call Eropa adalah

$$
C=e^{-n r \Delta t} \sum_{j=0}^{n}\left(\begin{array}{c}
n \\
j
\end{array}\right) p^{j}(1-p)^{n-j} \max \left\{S_{0} u^{j} d^{n-j}-K, 0\right\}
$$

dengan $S_{0}=S(0)$ dan $\left(\begin{array}{c}n \\ j\end{array}\right)=\frac{n !}{(n-j) ! j !}$ menyatakan banyaknya cara mendistribusikan $j$ sukses dalam $n$ percobaan. Ketiga buah parameter $u, d$ dan $p$ nilai-nilainya belum diketahui. Nilai 
parameter-parameter ini akan dapat ditentukan setelah memiliki persamaan yang menghubungkan ketiganya atau dengan suatu penambahan asumsi. Dengan menyamakan ekspektasi serta variansi model diskrit dan kontinu, diperoleh berbagai pilihan yang mungkin, dua di antaranya yang sering digunakan adalah $u d=1$ dan $p=\frac{1}{2}$.

Solusi untuk pilihan $u d=1$ diberikan oleh $d=\frac{1}{u}=\beta-\sqrt{\beta^{2}-1}$ dan $p=\frac{e^{r \Delta t}-d}{u-d}$ dengan $\beta=\frac{1}{2} e^{-r \Delta t}+e^{\left(r+\sigma^{2}\right) \Delta t}$ sedangkan solusi untuk pilihan $p=\frac{1}{2}$ diberikan oleh [9] $u=$ $e^{r \Delta t}\left(1+\sqrt{e^{\sigma^{2} \Delta t}-1}\right.$ dan $d=e^{r \Delta t}\left(1-\sqrt{e^{\sigma^{2} \Delta t}-1}\right)$

\section{Metode Penelitian}

Metode penelitian yang digunakan pada penelitian ini adalah studi literatur, pengumpulan data, pembuatan program komputer dari model-model yang diajukan di perangkat lunak Rstudio versi 3.6.1, analisis terhadap hasil yang diperoleh yaitu harga opsi call Eropa yang didapatkan dan penarikan kesimpulan. Data yang digunakan dalam penelitian ini adalah data sekunder. Sumber data yang digunakan pada penelitian ini data harga saham harian yang diperoleh melalui website https://www.finance.yahoo.com pada perusahaan PT Astra Agro Lestari Tbk dengan periode 1 Mei 2019 - 30 April 2020. Data harga penutupan harian saham PT Astra Agro Lestari Tbk dapat dilihat pada Gambar 1.

Data Harga Penutupan Saham Harian PT Astra Agro Lestari Tbk periode 1 Mei 2019 s.d 30 April 2020

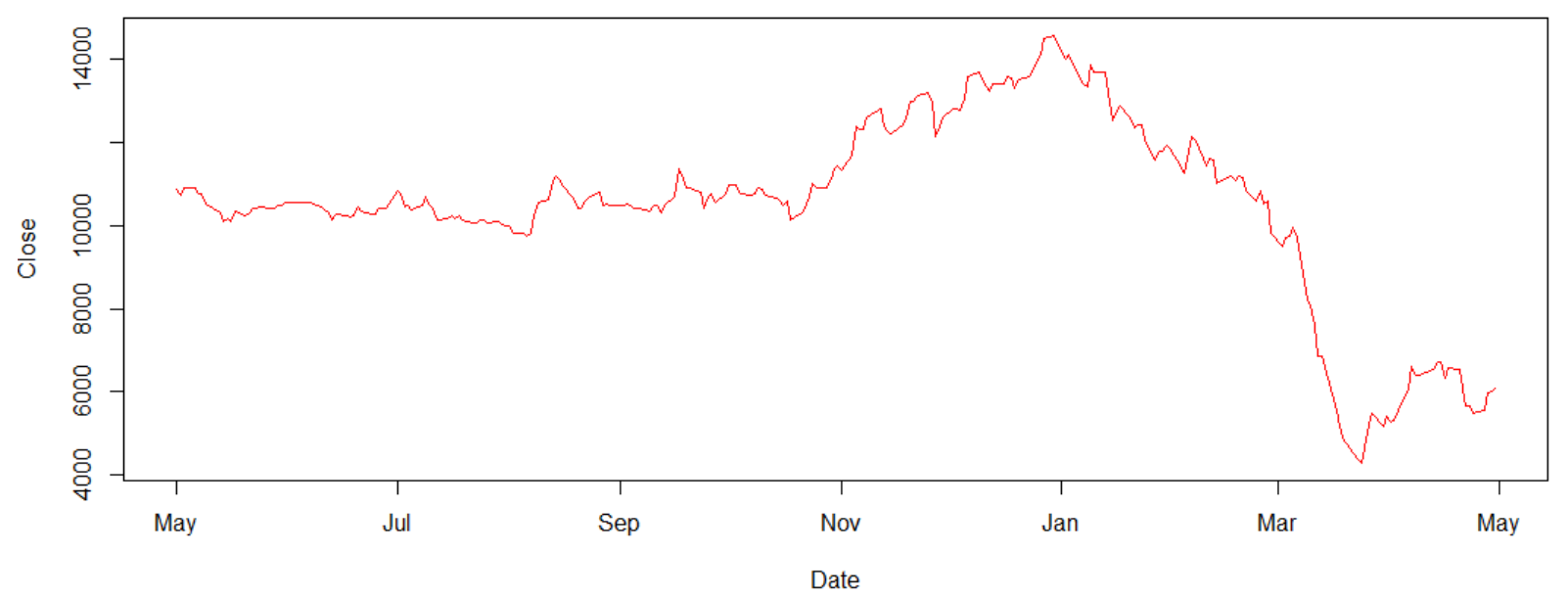

Gambar 1: Data Harga Penutupan Harian Saham PT Astra Agro Lestari Tbk

Prosedur penelitian dari penelitian ini sebagai berikut:

1. Mengambil data harga penutupan harian saham PT Astra Agro Lestari Tbk melalui website https://www.finance.yahoo.com

2. Menghitung volatilitas harga saham dengan cara sebagai berikut:

- Menghitung nilai return saham dan rata-rata return saham (diasumsikan return saham berdistribusi Normal)

- Menghitung volatilitas saham

3. Menentukan parameter-parameter yang digunakan pada penelitian ini, yaitu:

- Menentukan harga saham awal $\left(S_{0}\right)$

- Menentukan tingkat suku bunga $(r)$

- Menentukan harga kesepakatan $(K)$ 
- Menentukan waktu jatuh tempo (T)

4. Menghitung harga call opsi Eropa dengan menggunakan Model Black-Scholes.

5. Menghitung harga call opsi Eropa dengan menggunakan Monte Carlo dengan Teknik Antithetic Variate

6. Menghitung harga call opsi Eropa dengan menggunakan Model Binomial

7. Menganalisis harga call opsi Eropa yang diperoleh dari Antithetic Variate dan Binomial berdasarkan harga call opsi Eropa yang diperoleh dari Black-Scholes

8. Interpretasi dan kesimpulan

\section{Hasil dan Pembahasan}

\subsection{VolatIlitas Saham}

Untuk menghitung volatilitas saham, dimulai dengan menghitug nilai return PT Astra Agro Lestari Tbk pada saat waktu $t$. Pada saat $t=0$ nilai return adalah 0 . Diberikan contoh perhitungan nilai return saat $t=1$ sebagai berikut:

$$
R_{1}=\ln \left(\frac{10725}{10875}\right)=-0,01389
$$

Saat $t=2$, diperoleh nilai return saham sebagai berikut:

$$
R_{2}=\ln \left(\frac{10875}{10900}\right)=0,016185
$$

dengan cara yang sama, akan didapatkan nilai return saham untuk $t=3 \operatorname{s.d} t=255$. Adapun hasil perhitungan return saham disajikan pada Gambar 2 di bawah ini. II PlotZoom

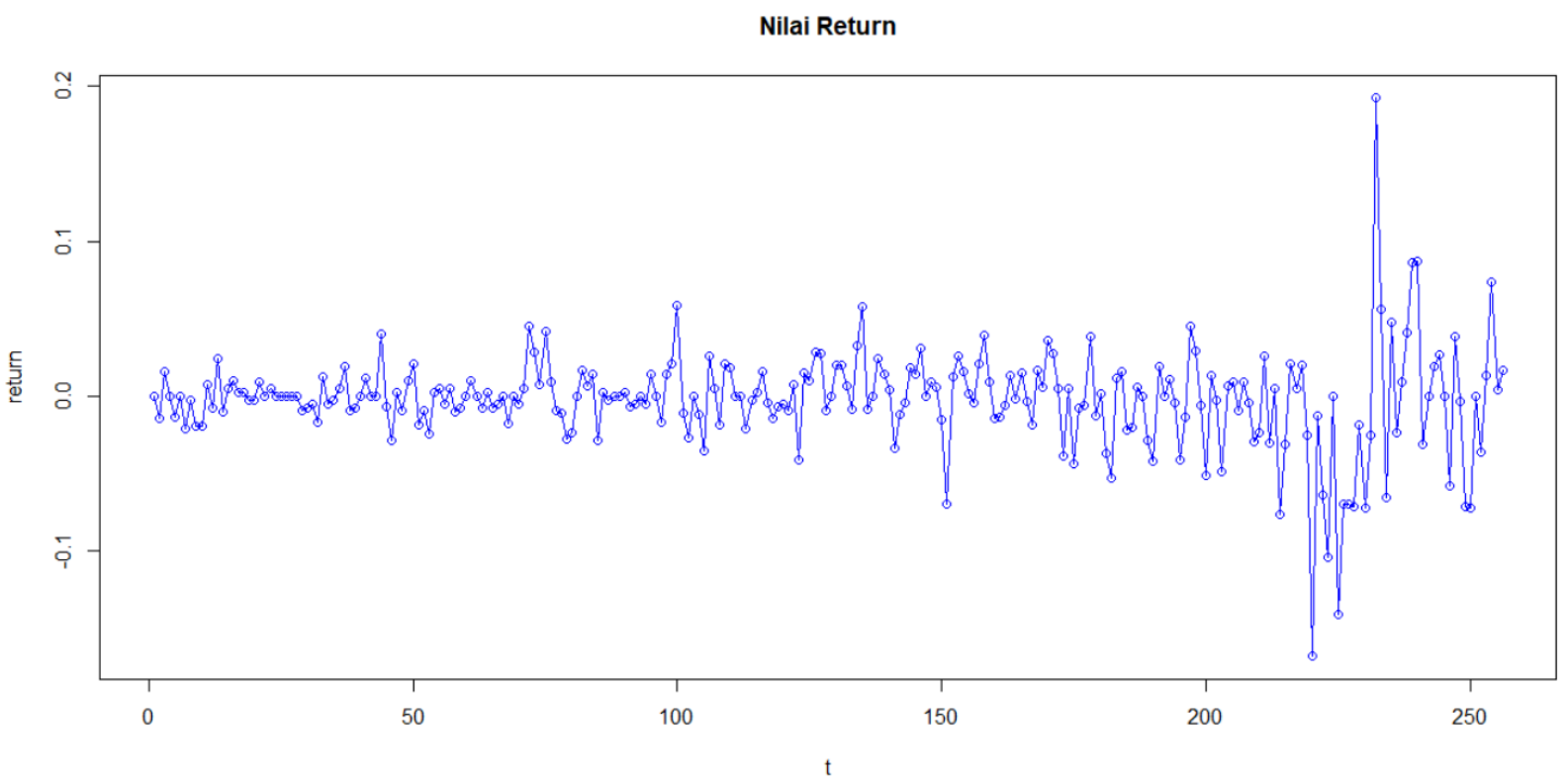

Gambar 2: Grafik Return Saham

Setelah menghitung nilai return saham, Langkah selanjutnya yaitu menghitung rata-rata return saham. Nilai rata-rata return saham sebagai berikut

$$
\overline{R_{t}}=\frac{1}{256} \cdot(0+(-0,01389)+0,016185+\cdots+0,016529)=-0,00226
$$

Langkah selanjutnya adalah menghitung nilai volatilitas saham. Nilai volatilitas saham sebesar 0,5088026 atau $50,88 \%$. 


\subsection{Harga Call Opsi Eropa}

Penentuan harga call opsi Eropa dipengaruhi oleh parameter-parameter yaitu harga saham awal $\left(S_{0}\right)$, tingkat suku bunga $(r)$, waktu jatuh tempo dan harga kesepakatan $(K)$. Harga saham awal $\left(S_{0}\right)=$ Rp. 10875, tingkat suku bunga yang digunakan pada penelitian ini adalah suku bunga yang dikeluarkan oleh Bank Indonesia sebesar 4,5\%, waktu jatuh tempo $(T)$ diperoleh dari dari lamanya kontrak opsi yaitu salama 1 tahun dan harga kesepakatan pada penelitian ini sebesar $K=$ Rp. 12000.

Penentuan harga call opsi Eropa PT Astra Agro Lestari Tbk menggunakan Black-Scholes pada software Rstudio diperoleh sebesar Rp. 1195,933. Harga tersebut dijadikan tolak ukur dalam menganalisis harga call opsi Eropa yang diperoleh dari Monte Carlo dengan Teknik Antithetic Variate dan Model Binomial.

Berdasarkan Tabel 1, diperoleh beberapa harga call opsi Eropa, yaitu untuk $\mathrm{M}=1000$ sebesar Rp. 1226,860, untuk $M=10000$ sebesar Rp. 1225,062, untuk $M=100000$ sebesar Rp. 1244,699, untuk $M=1000000$ sebesar Rp. 1219,875 dan untuk $M=10000000$ sebesar Rp. 1219,312. Harga call opsi Eropa dan standar error menggunakan Monte Carlo dengan teknik Antithetic Variate pada Rstudio dari PT Astra Agro Lestari Tbk dapat dilihat pada Tabel 1.

Tabel 1: Harga Call Opsi Eropa dengan Standar Error Menggunakan Antithetic Variate

\begin{tabular}{|c|c|c|}
\hline \multirow{2}{*}{ Banyaknya Simulasi $(\boldsymbol{M})$} & \multicolumn{2}{|c|}{ Monte Carlo-Antithetic Variate } \\
\cline { 2 - 3 } & Harga Call Opsi Eropa & Standar error \\
\hline 10000000 & 1219,312 & 0,5751809 \\
\hline 1000000 & 1219,875 & 1,819748 \\
\hline 100000 & 1244,699 & 5,786284 \\
\hline 10000 & 1225,062 & 18,44441 \\
\hline 1000 & 1226,860 & 56,1111 \\
\hline
\end{tabular}

Penentuan harga call opsi Eropa menggunakan model Binomial terlebih dahulu mencari nilai $\Delta t, u, d$, dan $p$. Pada Tabel 2 disajikan nilai-nilai $\Delta t, u, d$, dan $p$.

Tabel 2: Parameter untuk Perhitungan Harga Call Opsi Eropa menggunakan Model Binomial

\begin{tabular}{|c|c|}
\hline Parameter & Nilai Parameter \\
\hline$\Delta t$ & $\frac{T}{N}=\frac{1}{5}$ \\
\hline$u$ & 1.260136 \\
\hline$d$ & 0.7935649 \\
\hline$p$ & 0.4618279 \\
\hline
\end{tabular}

Sehingga harga call opsi Eropa untuk harga pelaksanaan sebesar Rp. 12000 sebagai berikut:

Tabel 3: Harga Call Opsi Eropa Menggunakan Model Binomial

\begin{tabular}{|c|c|}
\hline Banyak Langkah $(\boldsymbol{N})$ & Harga Call Opsi Eropa (Rp) \\
\hline 1 & 1239.653 \\
\hline 2 & 1237.412 \\
\hline 3 & 1237.392 \\
\hline 4 & 1236.324 \\
\hline 5 & 1235,216 \\
\hline
\end{tabular}


Berdasarkan harga call opsi Eropa yang dihasilkan oleh Model Black-Scholes, Antithetic Variate dan Binomial, terlihat bahwa Harga call opsi Eropa yang dihasilkan oleh Antithetic Variate dan Binomial konvergen ke harga call opsi Eropa yang dihasilkan oleh Model BlackScholes. Harga call opsi Eropa menggunakan Model Binomial sebesar Rp. 1235,216 dengan 5 langkah. Harga call Opsi Eropa menggunakan Antithetic Variate sebesar Rp. 1219,312 dengan standar error 0,5751809 semakin banyak simulasi, standar error yang dihasilkan konvergen ke nol.

\section{Kesimpulan}

Harga call opsi Eropa menggunakan Model Black-Scholes, Antithetic Variate dan Binomial masing masing yaitu Rp. 1195,933, Rp. 1219,312 dan Rp. 1235, 216. Semakin banyak simulasi pada Antithetic Variate menghasilkan harga call opsi Eropa yang kovergen ke harga call opsi Eropa yang dihasilkan oleh model Black-Scholes dengan standar error yang konvergen ke nol. Semakin banyak langkah pada model Binomial, menghasilkan harga call opsi Eropa yang kovergen ke harga call opsi Eropa yang dihasilkan oleh model Black-Scholes.

\section{Ucapan Terima Kasih}

Penelitian ini didukung oleh Hibah Penelitian Dosen Pemula PNBP UNG Tahun 2020 dari Universitas Negeri Gorontalo.

\section{Daftar Pustaka}

[1] K. A. Sidarto, M. Syamsuddin, and N. Sumarti, Matematika Keuangan. Bandung: ITB Press, 2019.

[2] B. Wang and L. Wang, "Pricing Barrier Options using Monte Carlo Methods," Uppsala University, 2011.

[3] L. H. T. W. Putri, K. Dharmawan, and I. W. Sumarjaya, "Penentuan Harga Jual Opsi Barrier Tipe Eropa Dengan Metode Antithetic Variate Pada Simulasi Monte Carlo," EJurnal Mat., vol. 7, no. 2, p. 71, 2018.

[4] S. Nadia and E. Sulistianingsih, "Penentuan Harga Opsi Tipe Eropa dengan Metode Binomial," Bul. Ilm. Math. Stat. dan Ter., vol. 07, no. 2, pp. 127-135, 2018.

[5] M. N. Mooy, A. Rusgiyono, and R. Rahmawati, "Penentuan harga opsi put dan call tipe eropa terhadap saham menggunakan model black-scholes," Gaussian, vol. 6, no. 3, pp. 407-417, 2017.

[6] D. Ruppert and D. S. Matteson, Statistics and Data Analysis for Financial Engineering, Second Edi. New York: Springer London, 2011.

[7] J. Gentle, "Journal of statistical software," J. Stat. Softw., vol. 11, no. 1, pp. 128-129, 2004.

[8] N. L. P. K. Wati, K. Dharmawan, and K. Sari, "Perbandingan Kekonvergenan Metode Conditional Monte Carlo dan Antithetic Variate dalam Menentukan Harga Opsi Call Tipe Barrier," E-Jurnal Mat., vol. 7, no. 3, pp. 271-277, 2018.

[9] S. A. Pramuditya, "Perbandingan Metode Binomial dan Metode Black-Scholes Dalam Penentuan Harga Opsi," J. Sainsmat, vol. V, no. 1, pp. 1-6, 2016. 